\title{
Penggunaan Alat Penurun Daya Listrik Untuk Mengurangi Biaya Operasional Pada Usaha Mikro Furniture (Mebel)
}

\author{
Machmud Effendy 1 \\ Universitas Muhammadiyah Malang, machmud@umm.ac.id \\ Zulfatman $^{2}$ \\ Universitas Muhammadiyah Malang, zulfatman78@gmail.com
}

\begin{abstract}
Abstrak
Kota Malang memiliki banyak UMKM (usaha mikro kecil dan menengah), salah satunya adalah usaha mikro furniture (mebel). Salah satu usaha mikro di kota Malang adalah "INDAH Mebel" milik bapak Budiyanto yang berada di Kelurahan Polowijen Kecamatan Blimbing. INDAH Mebel menghasilkan produk antara lain kursi, meja, lemari, kicthen set, interior set dll. Untuk memproduksi hasil mebel membutuhkan beberapa mesin listrik untuk proses pemotongan, penghalusan, pengeboran, pengecatan, dan finsihing. Saat ini INDAH Mebel mengeluhkan tingginya pembayaran listrik akibat banyaknya penggunaan mesin-mesin listrik. Sehingga untuk mengurangi beban pembayaran listrik, tim pengabdi menawarkan alat penurun daya listrik yang mampu menurunkan tegangan dan arus mesin listrik tanpa mengganggu kinerja alat.

Alat penurun daya listrik terdiri dari trafo penurun tegangan, rangkaian kontrol, rangkaian pembangkit tegangan terkontrol, sensor arus, dan fuse (pengaman).

Alat penurun daya listrik telah berhasil dibuat dan diimplementasikan pada usaha INDAH mebel.

Hasil pengujian menunjukkan bahwa alat penurun daya listrik mampu menurunkan tegangan dan arus listrik saat mesin-mesin listrik dioperasikan. Mesin-mesin listrik dioperasikan selama 7 jam sehari selama 26 hari dalam 1 bulan. Hasil perhitungan menunjukkan bahwa alat penurun daya listrik mampu menghemat daya listrik per bulan sebesar 413 Watt dan menghemat pembayaran listrik sebesar Rp. 110.025, dengan tarif pembayaran listrik dari PLN untuk kelas bisnis kecil sebesar Rp.1467/kWh

Kata Kunci: usaha mikro mebel, alat penurun daya listrik
\end{abstract}

\begin{abstract}
Malang City has many small and medium micro businesses, one of which is micro furniture business. One of the micro businesses in the city of Malang is "INDAH furniture" owned by Mr. Budiyanto who is in the Polowijen Sub-District of Blimbing District. INDAH Furniture produces products including chairs, tables, cabinets, kitchen sets, interior sets etc. To produce furniture, some electric machines are needed for the process of cutting, refining, drilling, painting, and finsihing. Currently INDAH Furniture complains of high electricity payments due to the large use of electric machines. So as to reduce the burden of electricity payments, the team offered an electric power lowering device that was able to reduce the voltage and current of the electric engine without interfering with the performance of the device.
\end{abstract}


Jurnal Pengabdian Kepada Masyarakat

An electric power lowering device consists of a voltage reducing transformer, a control circuit, a controlled voltage generator circuit, a current sensor, and a fuse.

Electric power lowering devices have been successfully created and implemented in INDAH furniture business.

The test results show that the electric power-lowering device is able to reduce the voltage and electric current when electric machines are operated. Electric machines are operated for 7 hours a day for 26 days in 1 month. The calculation results show that the electric power lowering device is able to save electricity per month by 413 Watts and save electricity payments of Rp. 110,025, with tariffs for electricity payments from PLN for small business classes of Rp.1467 / $k W h$

Keywords: micro-furniture business, electric power-lowering device

\section{Pendahuluan}

\section{Latar Belakang}

Berdasarkan data dari dinas Koperasi dan Usaha Mikro, kota Malang memiliki pusat usaha mikro furniture (mebel) yang berlokasi di kecamatan Blimbing, tepatnya di Keluarahan Tunjungsekar dan Kelurahan Polowijen(Malang, 2017). Salah satunya adalah milik bapak Budianto. Usaha mikro mebel yang dikelola oleh bapak Budianto merupakan usaha warisan yang sudah dimulai sejak kakeknya dan diawali pada tahun 1974, dan diberi nama INDAH Mebel. Awal berdirinya usaha ini, membuat kusen dan pintu dari bahan kayu. Saat ini, sudah bisa menghasilkan lemari kitchen set, perabot rumah tangga, kamar set, interior kantor,interior toko, interiro hotel, dan segala jenis pekerjaan dari kayu dan multiplex. Lokasi usaha dipusatkan di Jl. Polowijen I No. 271 RT.6 RW.2 Kelurahan Polowijen, Kecamatan Blimbing, Kotamadya Malang, Jawa Timur.

INDAH mebel membuat barang produksi berdasarkan pesanan, yang kebanyakan dilakukan oleh konsumen melalui telepon. INDAH mebel menindak lanjuti pesanan tersebut dengan strategi mendatangi pihak konsumen yang dilakukan langsung oleh pimpinan perusahaan. Pimpinan Perusahaan mengadakan komunikasi dan interaksi antar individu (personal selling), sehingga diketahui keinginan dan selera konsumen. Pimpinan INDAH mebel memberikan penjelasan informasi tentang produk yang diinginkan konsumen secara detail dan rinci, untuk mencapai tujuan yaitu kesepakatan jual beli diantara kedua belah pihak

Saat ini banyak pesanan dari hotel untuk membuat meja, kursi, bufet, dan tempat hiasan, mereka mampu membuat hasil mebel rata-rata sebanyak 30 buah dalam seminggu. Pemasaran yang dilakukan cukup efektif dan efisien, karena hampir setiap minggu sudah ada kantor, instansi, perusahaan, sekolahan maupun pribadi yang memesan mebel. Dengan demikian biaya pemasaran relatif rendah.

Menurut bpk Budianto, produksi mebel perlu ditingkatkan untuk memenuhi permintaan pasar yang semakin meningkat, tetapi dengan biaya produksi yang rendah, salah satunya dengan menurunkan biaya pembayaran listrik.

Untuk menjalankan usahanya, bapak Budianto dibantu dengan 10 karyawan. Sistem manajemennya masih konvensional, yaitu menerapkan manajemen keluarga. Dalam hal ini saudaranya dilibatkan dalam pengelolaan. Struktur organisasinya terbagi 
dalam beberapa divisi antara lain pemilik ( bapak Budianto) sekaligus sebagai manajer, pemasaran, tukang potong dan pasah, tukang bor, tukang cat, dan administrasi. Walaupun tidak mempunyai background pendidikan mebel, bapak Budianto ternyata cukup terampil dalam mengelola usahanya. Pengetahuan bidang mebel diperoleh dari ayahnya, membaca buku, mengikuti kegiatan kursus yang diadakan lembaga lain dan dari beberapa teman. Karyawan yang dilibatkan dalam usaha ini tidak semuanya mempunyai background pendidikan mebel. Tetapi dengan bimibingan dan arahan pemilik, maka karyawan mampu menjalankan tugasnya masing - masing.

Proses pembuatan hasil mebel terdiri dari proses pemotongan kayu atau multiplex menggunakan mesin potong, proses penghalusan hasil potong menggunakan mesin pasah, proses pengeboran, proses pengecatan dan finishing. Hampir seluruh pekerjaan membuat hasil mebel menggunakan mesin-mesin listrik yang membutuhkan daya listrik yang cukup besar. Setiap mesin-mesin listrik yang digunakan membutuhkan waktu pengoperasian rata-rata 7 jam. Menurut bapak Budianto, pembayaran listrik tiap bulan bisa mencapai 1 juta rupiah. Bagi usaha mikro seperti milik bapak Budianto, pembayaran listrik sebesar 1 juta cukup memberatkan. Sehingga diperlukan teknologi untuk mengurangi daya listrik saat mesin-mesin listrik dinyalakan.

Salah satu masalah yang dihadapi oleh INDAH mebel adalah tingginya pembayaran listrik setiap bulannya, sehingga menambah beban biaya operasional dalam membuat hasil mebel. Penyebab utama tingginya pembayaran listrik adalah pengggunaan mesin-mesin listrik yang digunakan untuk membuat hasil mebel. Oleh karena itu diperlukan penerapan teknologi untuk mengurangi tegangan dan arus listrik saat mesin-mesin listrik digunakan.

\section{Tujuan dan Manfaat}

Tujuan pengabdian ini adalah menghasilkan dan menerapkan alat penurun daya listrik untuk beban mesin mesin listrik yang digunakan pada usaha INDAH Mebel.

Sedangkan manfaat pengabdian ini adalah dapat mengurangi pembayaran biaya listrik PLN akibat penggunaan mesin-mesin listrik pada usaha INDAH mebel.

\section{Kajian Pustaka}

Mesin mesin listrik yang digunakan untuk memotong triplek, kayu pada usaha mebel termasuk jenis motor induksi bertegangan AC. Dimana motor ini mempunyai kekurangan antara lain daya listrik yang digunakan saat pertama dinyalakan memiliki daya awal yang cukup besar, sehingga diperlukan alat penurun tegangan dan arus listrik. Seperti yang sudah dianalisa oleh (Harumwidiah \& Kurniawan, 2015), motor induksi dapat diturunkan tegangan dan arusnya menggunakan teknik soft starter.

Hasil simulasi dan analisa menunjukkan bahwa tegangan AC dapat diturunkan dari $220 \mathrm{~V}$ menjadi $165 \mathrm{~V}$, dan arus maksimalnya juga turun dari $633 \mathrm{~A}$ menjadi $265 \mathrm{~A}$. Komponen utama yang digunakan adalah jenis IGBT (Insulated Gate Bipolar Trasnistor). 


\section{Metode}

Berdasarkan masalah yang dihadapi oleh INDAH mebel sebagai perusahaan mikro, yaitu tingginya biaya pembayaran listrik akibat penggunaan mesin-mesin listrik, maka berikut ini kami jelaskan penyelesaian masalah INDAH mebel menggunakan teknologi soft starter melalui tabel dibawah ini

Tabel 1. Rincian kelemahan permasalahan INDAH Mebel

\begin{tabular}{|c|c|c|c|}
\hline No & Permasalahan & Langkah Pemecahan & $\begin{array}{c}\text { Teknologi yang } \\
\text { Diterapkan }\end{array}$ \\
\hline 1 & $\begin{array}{l}\text { Besarnya daya listrik karena } \\
\text { penggunaan mesin-meisn } \\
\text { listrik sehingga memperbesar } \\
\text { tagihan listrik. }\end{array}$ & $\begin{array}{l}\text { Mengurangi daya listrik } \\
\text { untuk penggunaan } \\
\text { mesin-mesin listrik }\end{array}$ & $\begin{array}{c}\text { Menggunakan } \\
\text { rangkaian elektronika } \\
\text { daya }\end{array}$ \\
\hline 2 & $\begin{array}{c}\text { Belum adanya pengaman } \\
\text { untuk mesin listrik saat } \\
\text { beroperasi }\end{array}$ & $\begin{array}{l}\text { Menambahkan system } \\
\text { pengaman untuk mesin } \\
\text { listrik }\end{array}$ & $\begin{array}{c}\text { Menggunakan } \\
\text { rangkaian pengaman } \\
\text { mesin listrik seperti } \\
\text { fuse. }\end{array}$ \\
\hline
\end{tabular}

Untuk menyelesaikan permasalahan tersebut diperlukan tahapan dalam proses melaksanakan program pengabdian ini, antara lain:

a. Mengidentifikasi spesifikasi teknis mesin-mesin listrik yang digunakan dalam proses pembuatan mebel.

Spesifikasi teknis masing-masing mesin listrik yang digunakan harus diketahui seperti besarnya arus listrik, daya listrik, faktor daya, tegangan listrik, frekuensi, dan fasa listrik. Hal ini diperlukan agar tidak salah dalam menentukan spesifikasi teknis teknologi alat penurun daya listrik yang akan digunakan.

b. Memastikan bahwa teknologi alat penurun daya listrik yang digunakan sesuai dengan spesifikasi teknis untuk masing-masing mesin-mesin listrik.

Spesifikasi teknis teknologi alat penurun daya listrik yang digunakan harus lebih besar kemampuan dayanya (25\% lebih besar) dari masing-masing mesin listrik. Seperti mesin listrik untuk memotong kayu memiliki daya listrik sebesar 1000 Watt, maka daya listrik pada alat penurun daya listrik sebesar 1250 Watt. Hal ini dilakukan karena alat penurun daya listrik bekerja mengoperasikan mesin listrik pemotong, sehingga dibutuhkan spesifikasi teknik yang lebih besar.

c. Merakit teknologi alat penurun daya listrik yang sudah dilengkapi dengan sistem pengaman.

Setelah spesifikasi teknik alat penurun daya listrik terpenuhi, maka siap untuk dilakukan proses perakitan. Sebuah alat penurun daya listrik digunakan untuk semua mesin-mesin listrik. Untuk mengindari kerusakan alat penurun daya listrik saat terjadi gangguan listrik seperti hubung singkat beban, maka dibutuhkan sistem pengaman (fuse) yang dipasang pada masing-masing mesin listrik.

Untuk memperjelas proses perakitannya, ditunjukkan pada gambar 1 


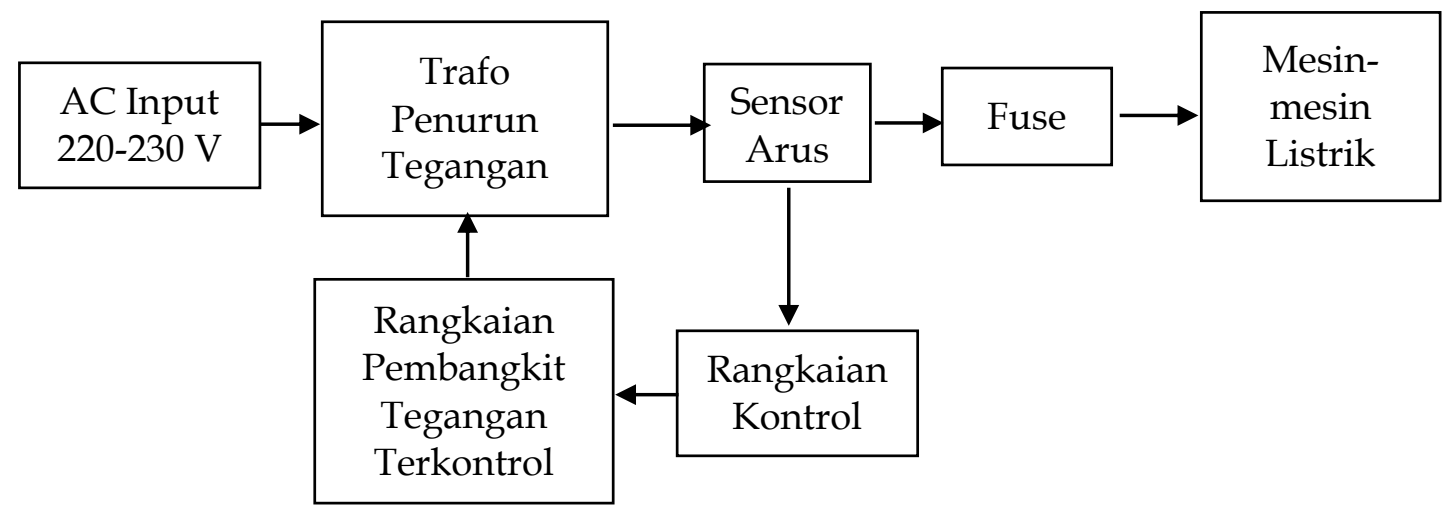

Gambar.1 Diagram Blok Perakitan Alat Penurun Daya Listrik

d. Menguji teknologi alat penurun daya listrik dan sistem pengamannya di laboratorium.

Sebelum teknologi alat penurun daya listrik diimplementasikan di lapangan, maka perlu diuji spesifikasi tekniksnya di laboratorium. Hal ini diperlukan untuk memastikan apakah alat penurun daya listrik telah berfungsi mengurangi daya listrik saat mesin listrik dinyalakan.

e. Mengimplementasikan teknologi alat penurun daya listrik dan sistem pengamannya di lokasi.

f. Menghitung selisih daya listrik dan $\mathrm{kWh}$ saat tidak menggunakan alat penurun daya listrik dan saat menggunakan alat penurun daya listrik

\section{Hasil dan Pembahasan}

\section{Menentukan Spesifikasi Alat Penurun Daya Listrik}

Spesifikasi teknik alat penurun daya listrik menyesuaikan dengan beban mesin listrik yang digunakan. Beban listrik yang digunakan sebanyak 5 buah antara lain: mesin listrik untuk pemotongan sebesar $1000 \mathrm{~W}$, mesin listrik untuk pasah sebesar $500 \mathrm{~W}$, mesin listrik untuk penghalusan sebesar $450 \mathrm{~W}$, bor listrik sebesar 250W, Kompresor listrik sebesar 1500W. Sehingga total daya mesin listrik sebesar $3700 \mathrm{~W}$. Maka Alat Penurun Daya listrik harus memiliki kapasitas daya minimal 3700W + $(25 \% \times 3200 \mathrm{Watt})=4625$ Watt.

Alat penurun daya listrik yang kami buat memiliki kapasitas daya sebesar $4700 \mathrm{~W}$

\section{Pengujian Alat Penurun Daya Listrik}

Pengujian alat penurun daya listrik dilakukan dengan mengukur tegangan dan arus listrik input dari PLN dan tegangan dan arus keluaran alat. Berikut ini adalah diagram blok pengujiannya. 


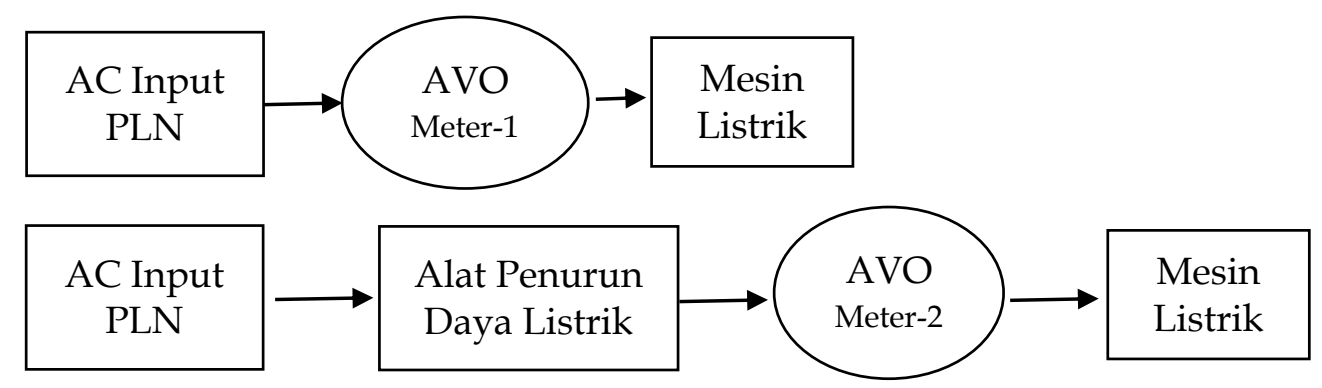

Gambar.2 Diagram Blok Pengujian Alat Penurun Daya Listrik

Tabel 2 menunjukkan hasil pengujiannya

Tabel 2. Rincian kelemahan permasalahan INDAH Mebel

\begin{tabular}{llll}
\hline \multirow{2}{*}{ No } & $\begin{array}{l}\text { Pembacaan } \\
\text { AVO Meter-1 }\end{array}$ & $\begin{array}{l}\text { Pembacaan } \\
\text { AVO Meter-2 }\end{array}$ & Keterangan \\
& V = 227 V & V $=216 \mathrm{~V}$ & \\
1 & $\mathrm{I}=15,5 \mathrm{~A}$ & $\mathrm{I}=14,38 \mathrm{~A}$ & 5 mesin listrik On \\
& $\mathrm{P}=3519 \mathrm{Watt}$ & $\mathrm{P}=3106 \mathrm{Watt}$ &
\end{tabular}

Tabel 2 menunjukkan bahwa besarnya tegangan dan arus keluaran alat penurun daya listrik melalui pembacaan AVO meter-2 lebih rendah dibandingkan dengan pembacaan AVO meter-1, daya yang diserap oleh beban menurun dari 3519 Watt menjadi 3106 Watt.

\section{Perhitungan $\mathrm{kWh}$ Listrik}

Untuk mengetahui besarnya biaya listrik yang harus dibayar, maka perlu dihitung besarnya kWh (Kilo Watt Hour) listriknya, dengan rumus (Gunawan, 2018)

$\mathrm{kWh}$ listrik = daya listrik $\mathrm{x}$ lama pemakaian mesin listrik

Merujuk pada tabel 2, maka daya yang diserap beban, jika tanpa alat penurun daya listrik sebesar (Muhammad, 2007)

$\mathrm{P}=\mathrm{V} . \mathrm{I}=227 \times 15.5=3519$ Watt $(3,519 \mathrm{~kW})$

Jika lama pengoperasian mesin-mesin listrik rata-rata 7 jam sehari $(7 \times 26=182$ jam dalam sebulan), maka dapat dihitung besarnya kWh nya

$\mathrm{kWh}=3,519 \times 182=640 \mathrm{kWh}$

Mengacu pada Peraturan Kemesntrian ESDM tentang tarif daya listrik PLN untuk bisnis kecil, maka biaya per kWh sebesar Rp. 1.467/kWh.

Sehingga biaya listrik yang harus dikeluarkan sebesar $640 \mathrm{kWh} \times$ Rp. $1.467=$ Rp. 938.880 
Jurnal Pengabdian Kepada Masyarakat

Sedangkan jika menggunakan alat penurun daya listrik, maka daya yang diserap beban sebesar:

$\mathrm{P}=\mathrm{V} . \mathrm{I}=216 \times 14.38=3106$ Watt $(3,106 \mathrm{~kW})$

$\mathrm{kWh}=3,106 \times 182=565 \mathrm{kWh}$

$565 \mathrm{kWh} \times \mathrm{Rp} .1 .467=$ Rp. 828.855

Sehingga selisih pembayaran tiap bulan, setelah pemakaian alat penurun daya listrik sebesar Rp. 938.880 - Rp. 828.855 = Rp. 110.025
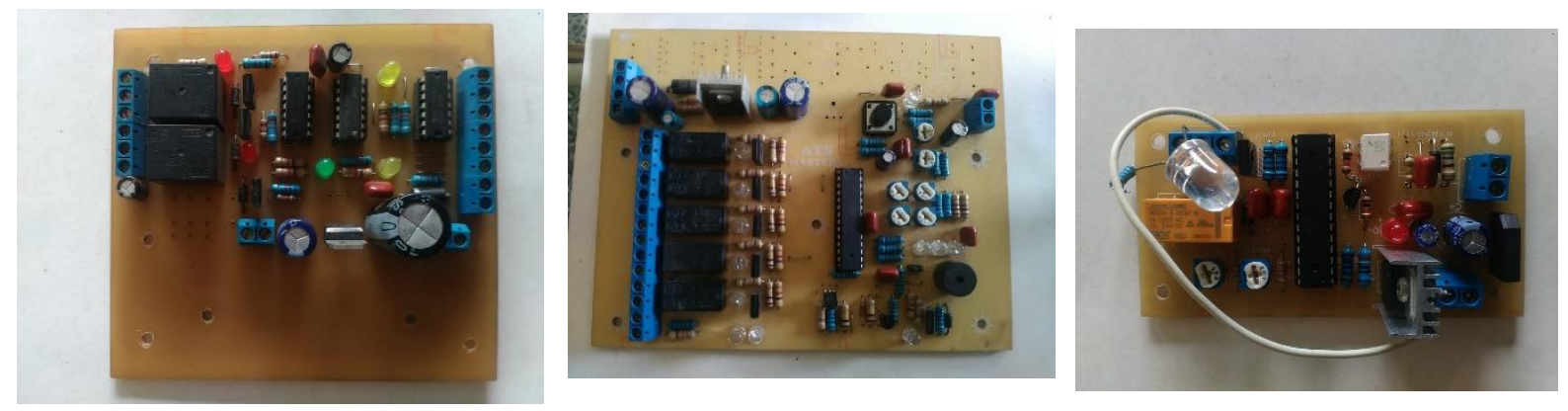

Gambar.3 Rangkaian Kontrol, Sensor Arus, dan Rangkaian Pembangkit Tegangan Terkontrol

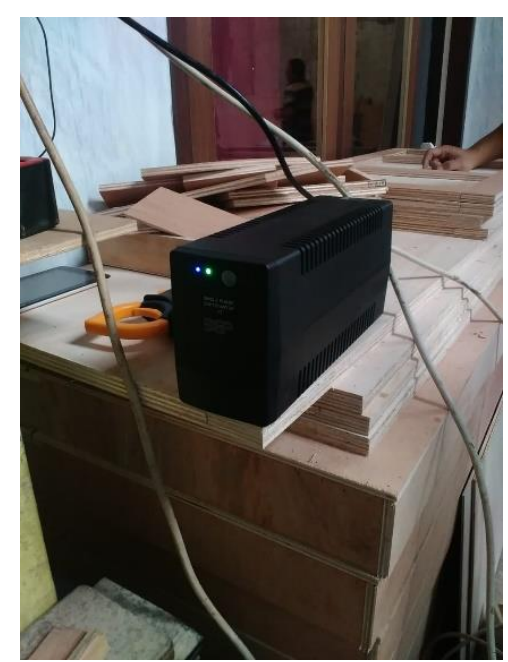

(a)

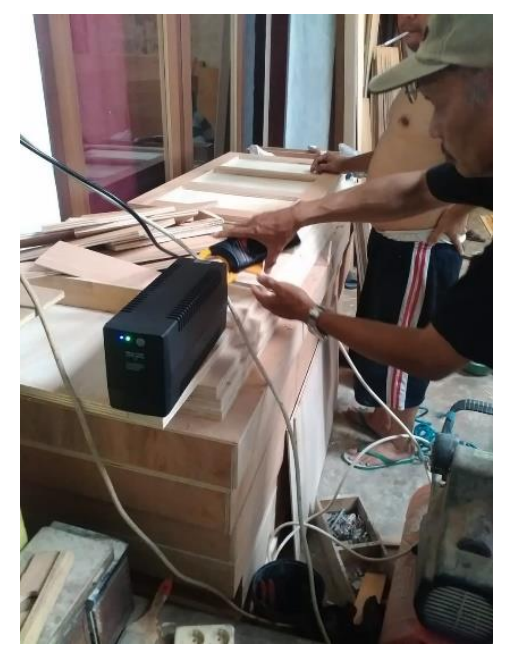

(b)

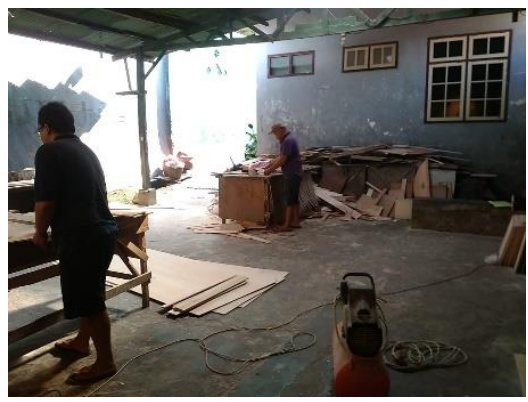

(c)

Gambar.4 (a) Tampak Alat Penurun Daya Listrik

Gambar.4 (b) Pengukuran Arus dan Tegangan

Gambar.4 (c) Pekerja Mebel Sedang Mengoperasikan Mesin Potong

\section{Simpulan dan Rekomendasi}

Hasil mebel dibuat dengan bantuan mesin-mesin listrik yang membutuhkan daya listrik cukup besar. Alat penurun daya listrik yang telah dibuat mampu menurunkan tegangan dan arus listrik saat mesin-mesin listrik dioperasikan. Sehingga mengurangi penggunaan daya listrik dan kWh listrik. Dari hasil perhitungan menunjukkan bahwa 
terjadi penghematan daya listrik setiap bulan sebesar 413 Watt dan menghemat pembayaran listrik sebesar Rp. 110.025.

\section{Acknowledgements}

Kami ucapkan terima kasih kepada Direktorat Penelitian dan Pengabdian Masyarakat Universitas Muhammadiyah Malang yang telah mendanai pengabdian ini, sehingga berhasil melaksanakan pengabdian dengan lancar.

\section{Daftar Pustaka}

Gunawan, D. (2018). Studi Komparasi Kwh Meter Pascabayar Dengan Kwh Meter Prabayar Tentang Akurasi Pengukuran Terhadap Tarif Listrik Yang Bervariasi. Setrum : Sistem Kendali-Tenaga-Elektronika-Telekomunikasi-Komputer, 7(1), 158-168.

Harumwidiah, A., \& Kurniawan, A. (2015). Modeling and Analysis of AC-AC Soft Starter for Induction Motor Based on Thyristor and IGBT. ASEAN Journal of Systems and Engineering, 3(2), 60-64.

Malang, D. K. dan usaha mikro. (2017). Peta Usaha Mikro, kecil dan menengah kota malang (Edisi Kedu). Laporan Statistik Industri Mebel Kota Malang.

Muhammad, R. (2007). POWER ELECTRONICS HANDBOOK (Second). Elsevier. 